\title{
Experience of hormone replacement therapy among women of Sarawak, Malaysia
}

\author{
S. A. R. Syed Alwi, Z. Siti Rubiah*, P. Y. Lee, P. S. Mallika and M. N. Md Haizal
}

Department of Family Medicine, Faculty of Medicine and Health Sciences Universiti Malaysia Sarawak, Kuching; *Faculty of Resource Sciences and Technology, Universiti Malaysia Sarawak, Sarawak; ${ }^{\dagger}$ Department of Obstetrics and Gynecology, Cyberjaya University College of Medical Sciences, Cyberjaya, Malaysia

Key words: HORMONE REPLACEMENT THERAPY, KNOWLEDGE, USAGE OF HRT, SARAWAK, MALAYSIA

\begin{abstract}
Objectives To determine the usage of hormone replacement therapy (HRT) and knowledge about HRT among women of Sarawak in Malaysia.

Methods A prospective study using a face-to-face interview was conducted on 356 randomly selected Sarawakian women aged between 40 and 65 years.

Results The mean age of respondents was $50.83 \pm 6.30$ years and the mean age of menopause was $51.28 \pm 2.28$ years. Twenty-three percent of women were premenopausal, $39.6 \%$ perimenopausal and $37.4 \%$ postmenopausal. Only $36 \%$ of the respondents were aware of the existence of HRT; this is especially among those who were younger women, better educated and working. The main sources of information on HRT were friends and relatives (92.2\%), newspapers/magazines $(89.1 \%)$ and television/radio (64.1\%). HRT usage among respondents was low $(8.1 \%)$, mainly for relief of menopausal symptoms such as night sweats $(100 \%)$, mood swings $(93.1 \%)$, irritability $(93.1 \%)$, and hot flushes $(86.2 \%)$; only $24.1 \%$ used it for the prevention of osteoporosis. All women on HRT had taken HRT for less than 3 years. The main reason given for not being on HRT was that it was not recommended by their doctors $(56.6 \%)$; only $8.3 \%$ worried about the side-effects and $4.3 \%$ were on other forms of treatment.

Conclusions The use of and knowledge about HRT among women of Sarawak were found to be low in our study. The main sources of information about HRT are from friends/relatives and the mass media. Health-care providers should play an important role in promoting, counseling and health education regarding HRT needs to rectify these problems.
\end{abstract}

\section{INTRODUCTION}

During the past few years, many women and doctors have revised their opinions of hormone replacement therapy (HRT) for menopausal symptoms, and a substantial number of individuals have discontinued its use because of concerns about side-effects, especially after the release of the Women's Health Initiative study, which links increased risk of developing coronary heart disease events, breast cancers, strokes and pulmonary emboli for the group taking HRT $^{1,2}$.

Currently, the primary indication for systemic HRT is treatment of moderate to severe menopausal symptoms (i.e. vasomotor symptoms and sleep disruption from vasomotor symptoms) ${ }^{3}$. Thus, the decision to use HRT for an extended period of time is complex, as its 